\title{
Sizing method by optimization with energy management - application to electrical hybrid train
}

\author{
Marie POLINE(*)(**), Laurent GERBAUD**, Julien POUGET*,Frédéric CHAUVET*,Ali CASTAING* \\ * Innovation \& Research Department, SNCF, Paris, FRANCE \\ firstName.lastName@sncf.fr \\ ** Univ Grenoble Alpes, CNRS, Grenoble INP1, G2Elab, 38000 Grenoble, FRANCE \\ firstName.lastName@g2elab.grenoble-inp.fr
}

\begin{abstract}
In France, most of the trains are electrical and some are fed by $1500 \mathrm{~V}$ DC voltage. When a train is travelling, the power consumption creates a voltage drop. Therefore, below a certain limit, the train has to slow down its speed. This limitation prevents the increase of traffic in some area which needs an electric reinforcement. This paper proposes to use embedded storage systems to support the voltage of the catenary. The main issue is: how to size such an energy storage system? In this way, several aspects (e.g.: the energy management strategy) have to be taken into account. The paper deals with an optimization-based sizing method for the embedded energy storage systems. The proposed method takes into account the energy management strategy in the sizing by optimization. A comparison is made between the use of batteries or supercapacitors.
\end{abstract}

Keywords: electric hybrid train, energy management, optimization, sizing, SQP

\section{INTRODUCTION}

In France, only $50 \%$ of the railway lines are electrified but it represents $85 \%$ of the railway traffic [1]. Most of these lines are supplied using a voltage of $25 \mathrm{kV}$ AC but some regional lines used 1500V DC [2]. For this mode of supply, non-reversible substations are dispatched along the railway line. They are connected to the national electricity transmission network. The electricity goes throughout a transformer and an AC/DC static converter to the overhead contact line (catenary, see Figure 1).

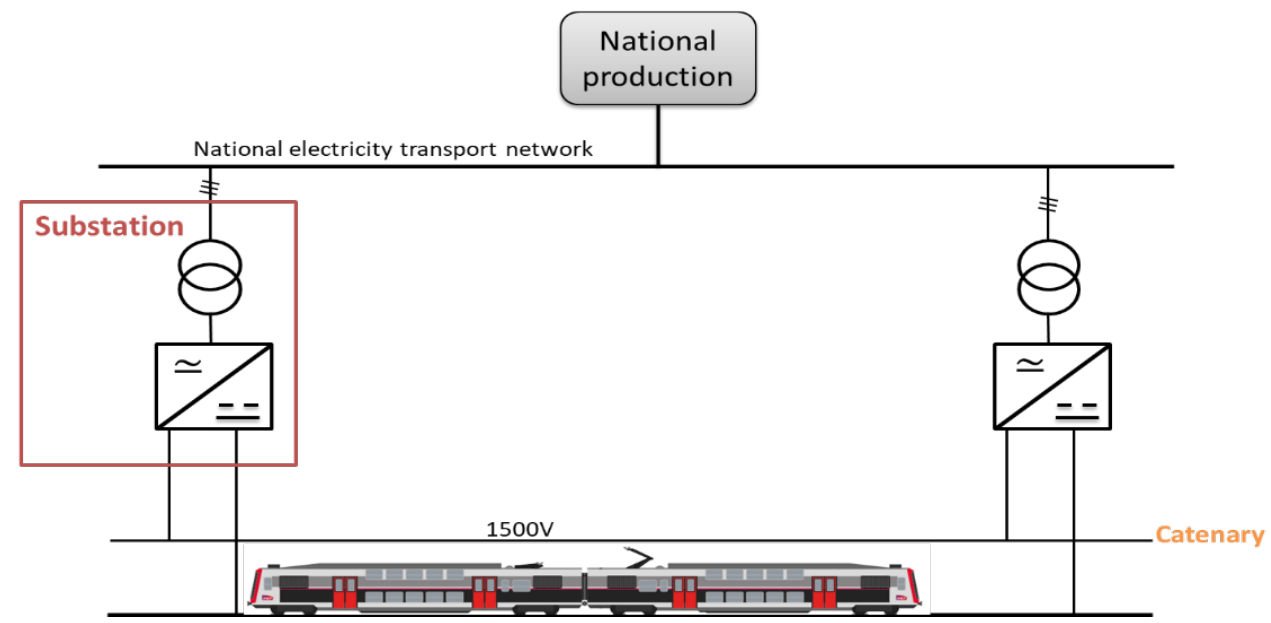

Figure 1: Railway line in $1500 \mathrm{VDC}$

However, such a line has some limitations. Indeed, the consumption of energy used to feed the electrical motor of the train creates a voltage drop. Below a certain threshold, this consumption has to be reduced to avoid the activation of the electrical protections. Thus, the train is no longer supplied and slows down. Since, the trains have to preserve a safety distance between them, if one train slows down, the following trains have to do the 
same, preventing the adding of another train and so, the traffic increasing. However, SNCF (the French Railway Company) has to face a growing traffic demand and reaches the limitation of its infrastructures [3]. So, it is necessary to reinforce the electric lines. Several methods are possible such as [4], [5]:

- increasing the voltage of the substation (up to $1800 \mathrm{~V}$, see (1) in Figure 2),

- $\quad$ adding paralleling station (see (2) in Figure 2),

- increasing the catenary section (see (3) in Figure 2),

- $\quad$ increasing the number of electric substations (see (4) in Figure 2),

- adding stationary storage systems besides the railway tracks [4] (recent solution, see (5) in Figure 2).

The first solution (see (1) in Figure 2) is the easiest to implement since all the components exist in the network. However, it is not possible to increase indefinitely this voltage (up to $1800 \mathrm{~V}$ ). The second solution, see (2) in Figure 2, connects two catenaries with switches to increase, virtually, the catenary diameter. This will allows to transfer more power. This solution is widely used but it will not increase the voltage. The third solution, increasing the catenary section (see (3) in Figure 2), will have the same effect than the second solution but costs a lot. The fourth solution (see (4) in Figure 2) is the more efficient but also the more expensive. Thus, it is considered only if the traffic increase need is huge. The last solution, stationary storage system (see (5) in Figure 2), is still studied at SNCF but presents a good compromise in terms of cost and efficiency to support the voltage.

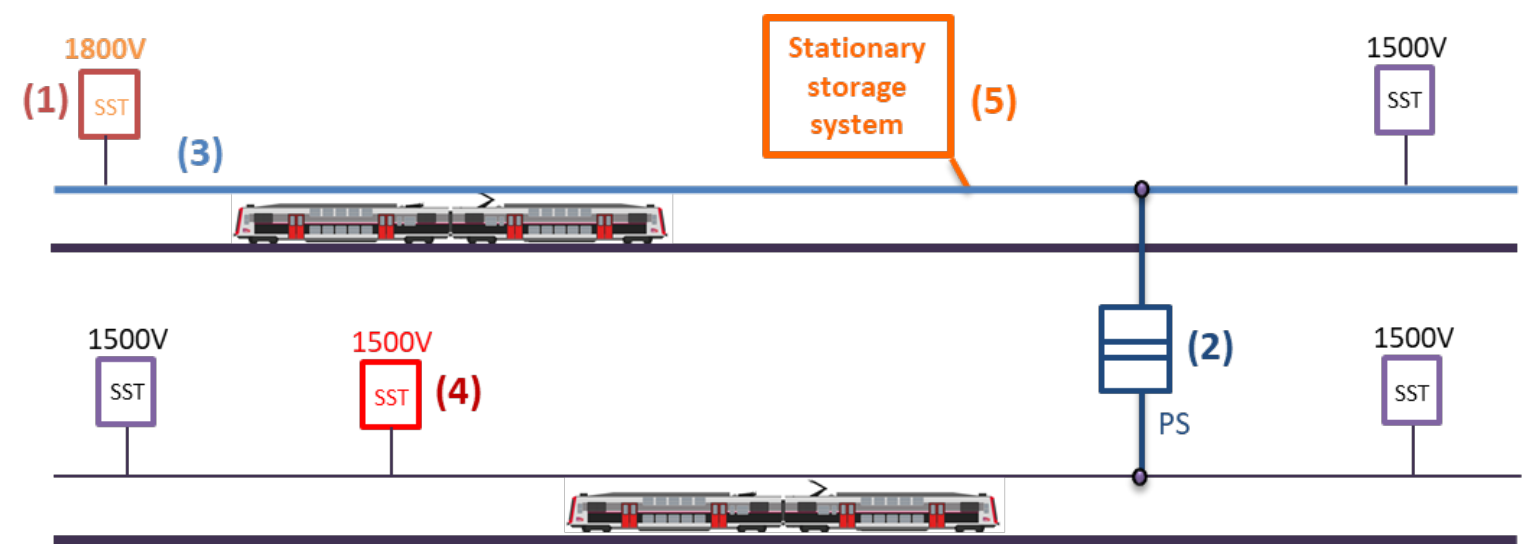

Figure 2: Solutions to reinforce the railway electric line

However, all of these solutions will solve the problem only locally. Thus, it is possible, using one of the five solutions, to reinforce the weakest point of the railway electric line but the action is limited to a specific area. Therefore, it might be necessary to install several of them on a same railway electric line.

Thus, the paper proposes another solution: to add embedded storage system in the trains (see Figure 3). They will help to support the catenary voltage by providing a part of the power requested by the trains. This way, the power that transits through the catenary is reduced and so, the voltage drops are smaller. The main advantage of this solution is that it is not limited to a specific area. 


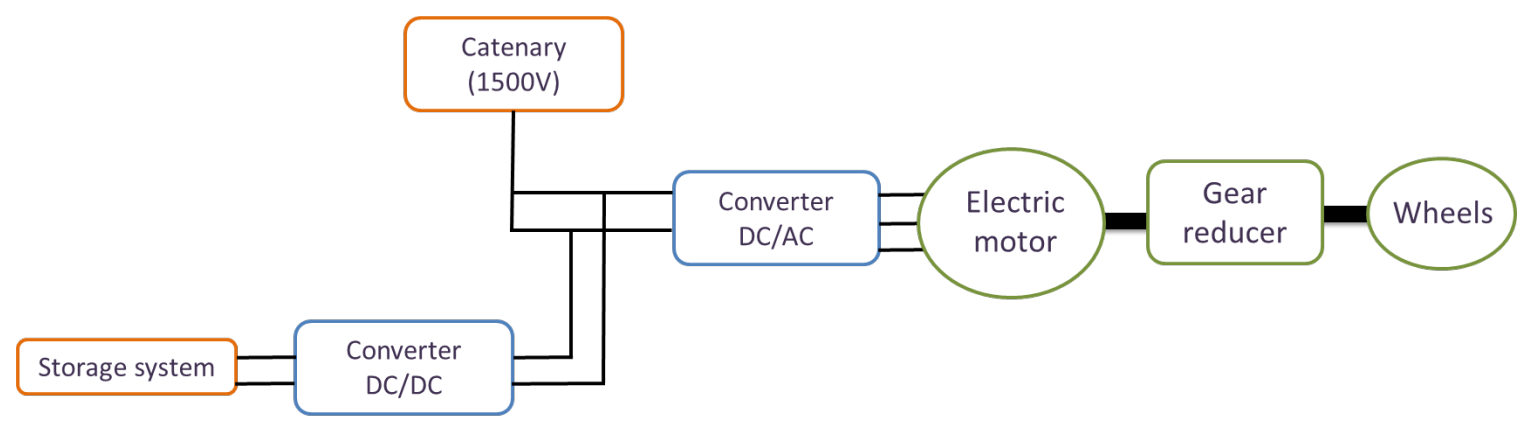

Figure 3: Architecture of the hybrid electric train

Two problems appear:

- What is the sizing of the embedded storage system?

- What is the energy management to apply to the catenary and the embedded storage element to respect the catenary voltage limitations with a minimal storage system?

The paper focuses on a method to determine both the storage system sizing and the energy management by using an optimization approach.

\section{SIZING APPROACH}

\section{Combined optimization}

To determine the sizing of the storage elements using an optimization approach, usual methods separate the sizing and the energy management (see Figure 4). However, a previous study [6] shows that the energy management has a strong influence on the sizing. Indeed, it determines the power and the energy profiles of the energy sources. From these profiles, it is possible to deduce specifications (e. g. a maximum peak power) that the energy source has to fulfill. On the other hand, the sizing imposes some restrictions to the energy management. Indeed, the characteristics of an energy source (e. g. maximum discharging power) give constraints that the energy management has to respect. So, an energy management method is added to the optimization-oriented model to take into account this mutual influence (see Figure 5).

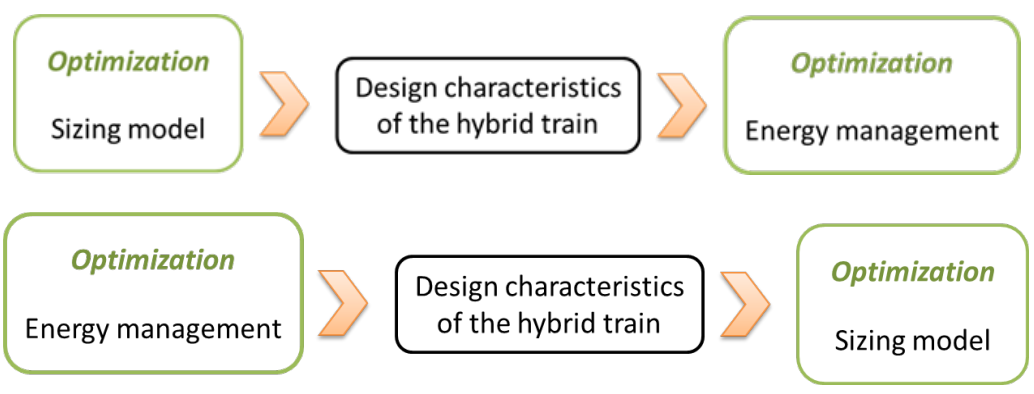

Figure 4: Usual sizing methods

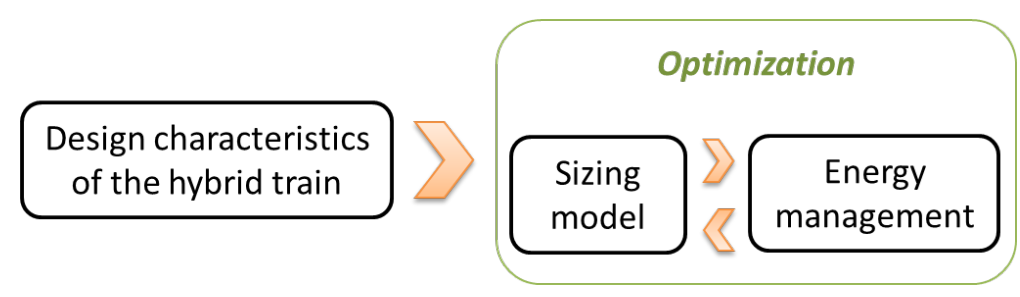

Figure 5: Combined optimization method 


\section{Optimization on an operating cycle}

To determine the energy management, a time profile has to be provided to the model (railway mission). However, the studied system is not composed of one train but of a railway line where several trains travel on it. Each train consumption will influence the voltage of the electrical line. So, it is necessary to take into account all the trains to know the total voltage drop. Thus, the railway mission contains the power consumed by each train and their position at each discretization step (time step of 1s, see Figure 6a and Figure 6b).

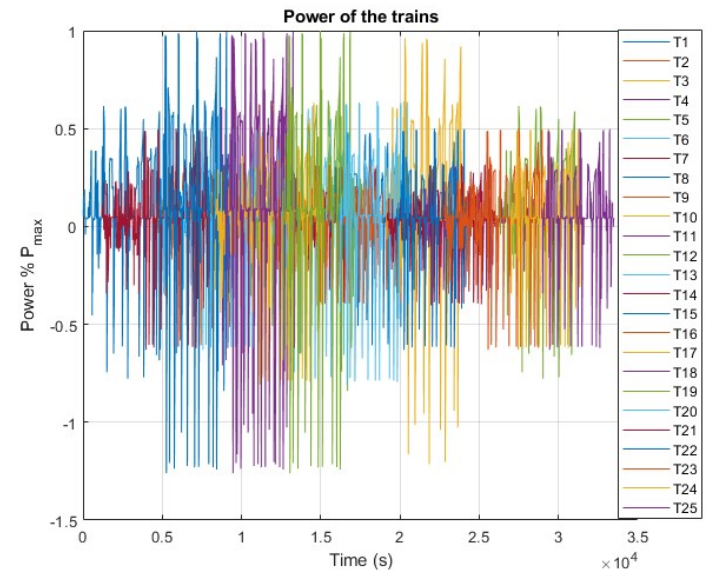

Figure 6a: Railway mission: power

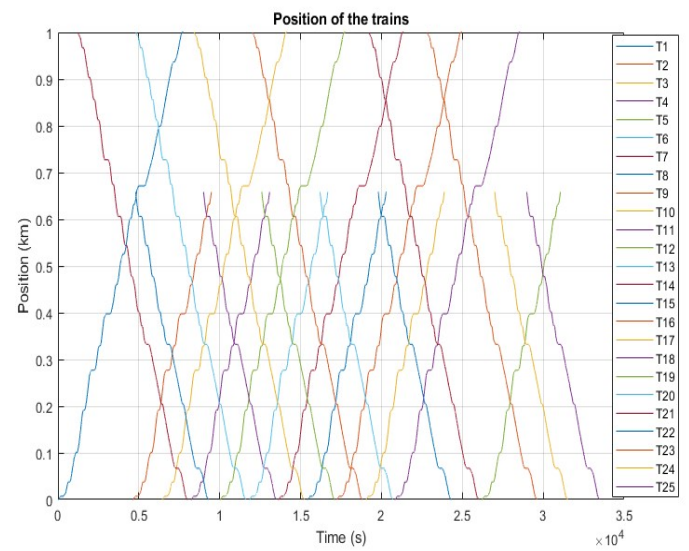

Figure 6b: Railway mission: position

\section{MODELLING}

\section{Nodal representation}

The nodal representation is a widely used method to represent an electric railway line and their trains [4], [7], [8], [9], [10], [11]. Nodes of current (see Figure 12) symbolize the different components (train, substations, paralleling station..., see Figure 7). The catenary between two nodes corresponds to an electrical resistance, which its value depends on the length of the line portion and the catenary characteristics (diameter and composition). 

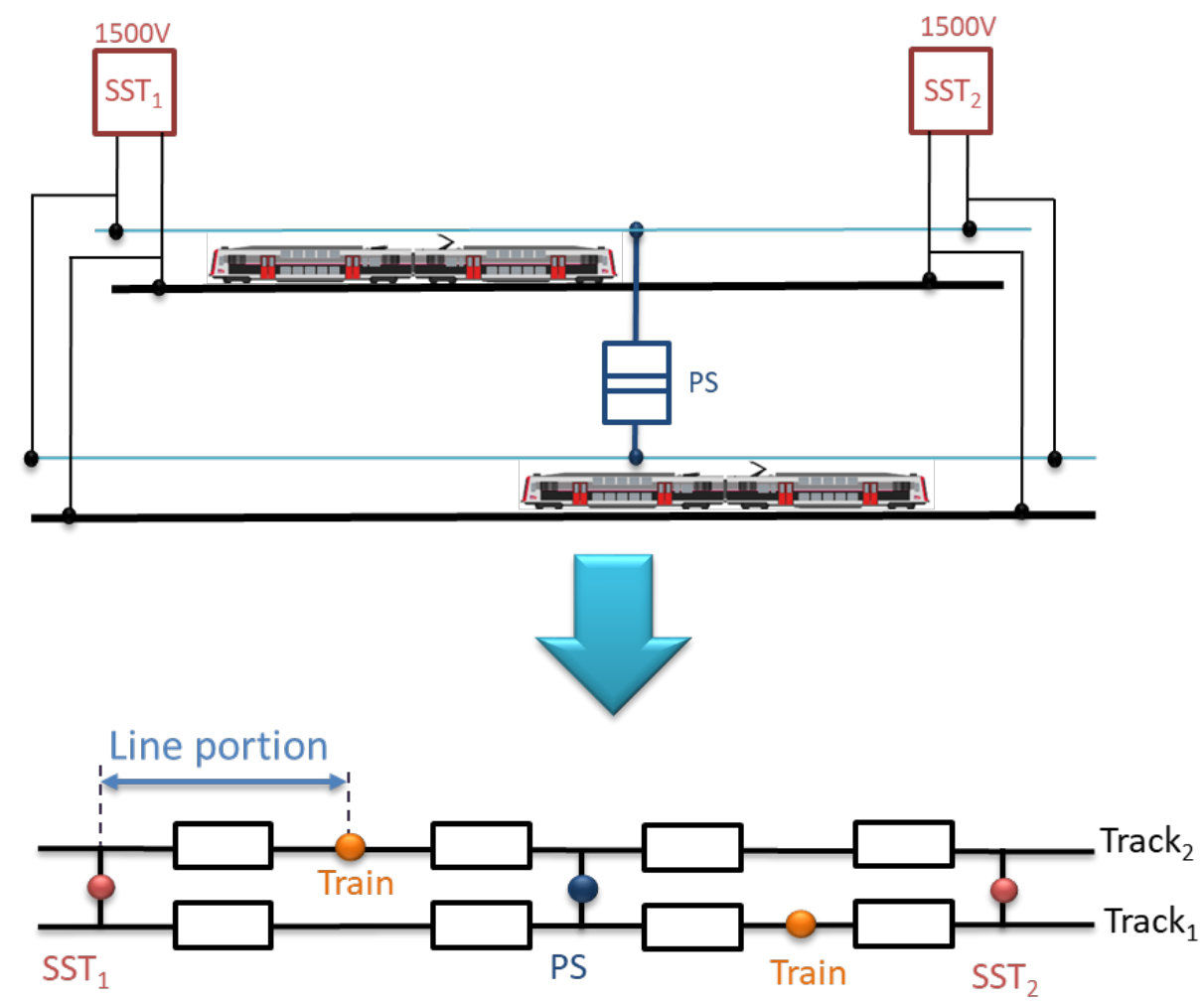

Figure 7: Nodal representation

With:

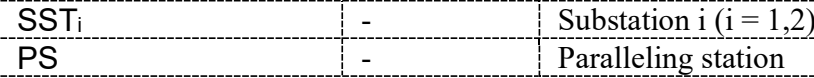

There are several possible nodal representations: the nodes can be fixed or mobile, their number can change or not during the simulation. A possible method is to fix the number of nodes and their positions before starting the simulation or the optimization process. The power requested by a train is split between the two closest nodes (see Figure 8). The main advantage of this solution is that the equations from the modeling is the same during all the railway mission. However, even if the global solving is exact, it does not give the exact voltage drop at the train position.

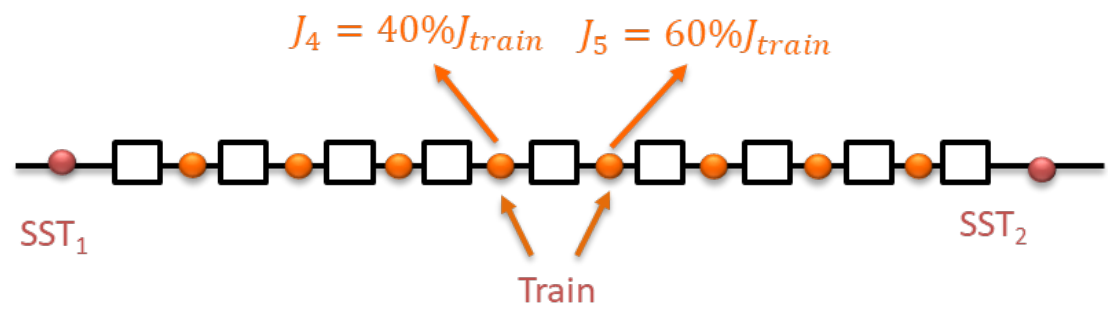

Figure 8: Nodal representation with fixed node

With:

\begin{tabular}{|c|c|c|}
\hline $\mathrm{SST}_{\mathrm{i}}$ & - & Substation $\mathrm{i}(\mathrm{i}=1,2)$ \\
\hline $\mathrm{J}_{\mathrm{i}}$ & $(\mathrm{A})$ & Current requested at the node $\mathrm{i}(\mathrm{i}=4,5)$ \\
\hline$J_{\text {train }}$ & $(\mathrm{A})$ & Current requested by the train \\
\hline
\end{tabular}


The most common nodal method used mobile nodes [8]-[10]. The electrical component of the line (substation and paralleling station) are represented using fixed node. However, a mobile node symbolizes the train: its position evolves according to the position of the train during the railway mission. Therefore, such a node appears between two substations when the train is between them and disappears when the train has moved forward (see Figure 9). Thus, the equations system changes at each time step but the voltage drop is known with accuracy at the train node.

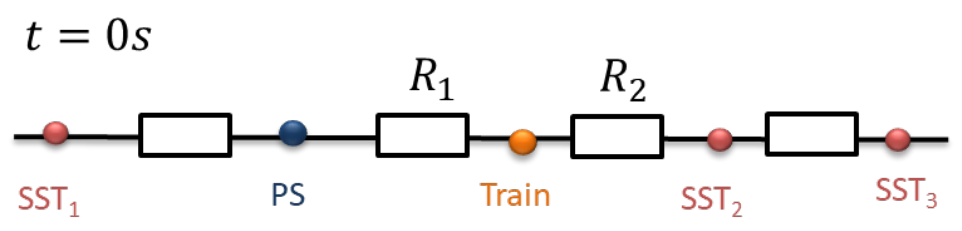

Direction of the train

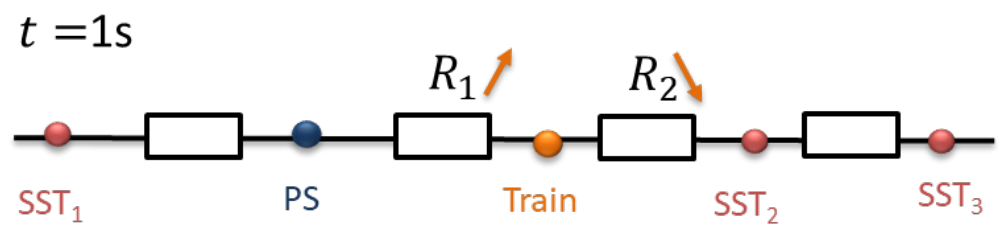

Direction of the train

$$
t=100 \text { s }
$$

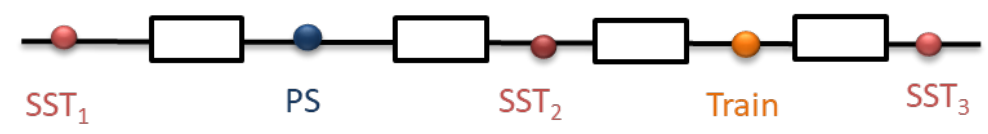

Direction of the train
- Suppression of the node between PS and $S S T_{2}$

- Apparition of a node between $S S T_{2}$ and $S S T_{3}$

Figure 9: Nodal representation with mobile cutting

The last method allows to combine the advantages of both methods: a fixed system of equations but a good accuracy to know the voltage drop. This method is presented in the next section and has been used to represent the railway line.

\section{Fixed cutting and mobile nodes}

Each node represents a component of the line (train, electric substation, paralleling station). Since the trains are moving, the nodes for these subsystems change their position to follow the position of the trains on the railway line (see Figure 11). The electric elements (substation and paralleling node) stay still, so, a fixed node represents each one (see Figure 10). The number of nodes is fixed for all the time steps, so, the equations system is the same during all the railway mission. However, the change of position affects the value of the electrical resistances, which evolve according to the distance between two nodes. Moreover, the use of mobile nodes allows to know with a good accuracy the voltage drop at the train position. 


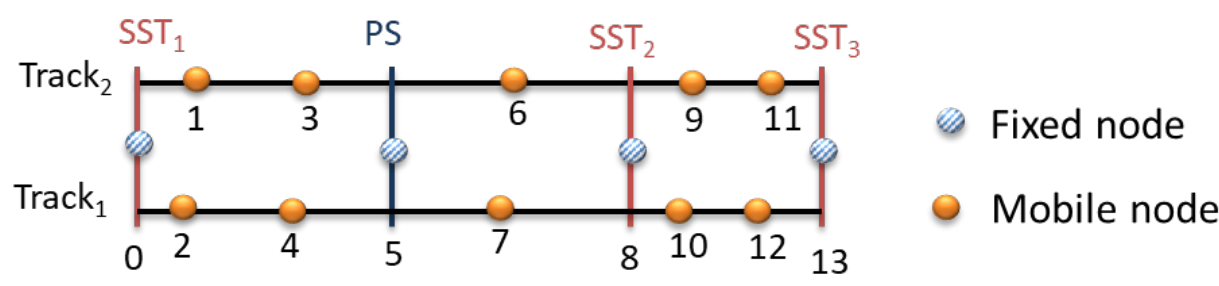

Figure 10: Nodal representation with variable impedance
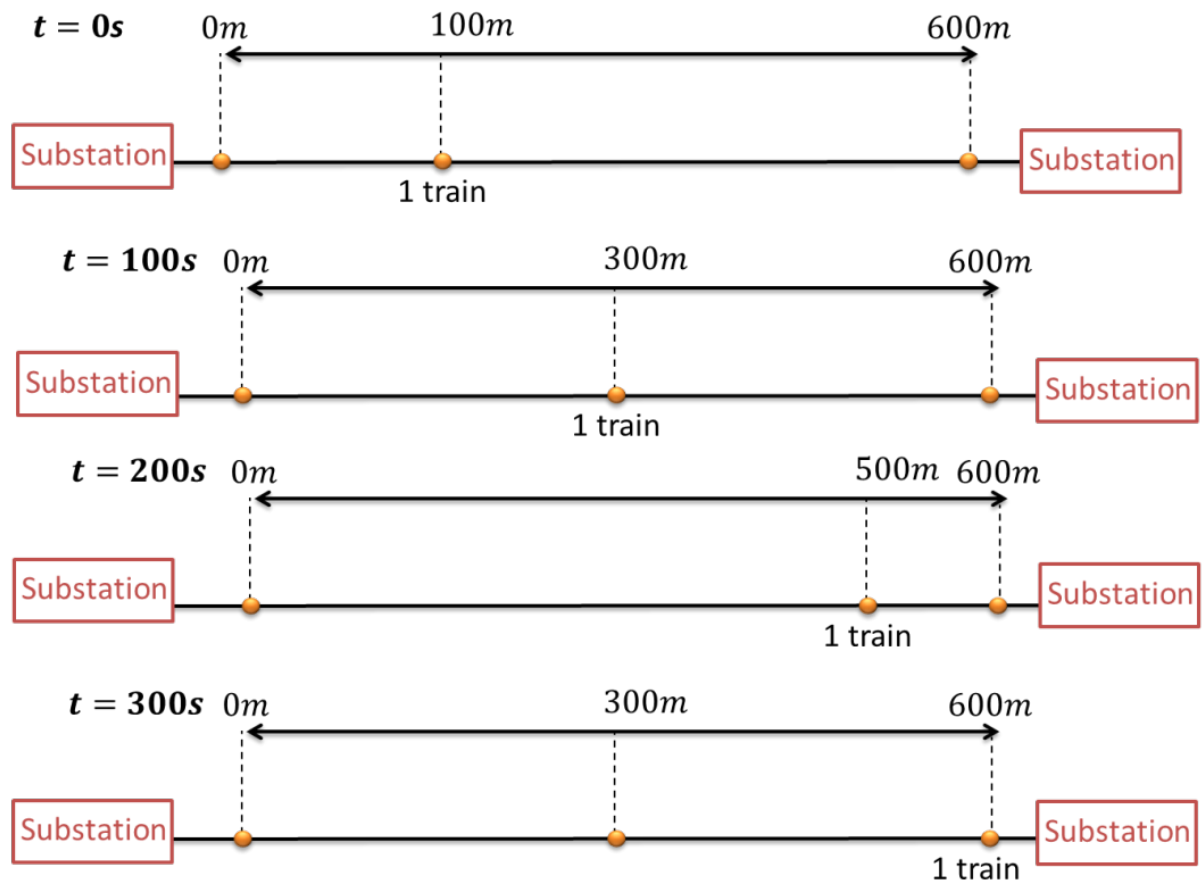

Figure 11: Example of the evolution of the node position according to the train position

The train is represented with a node of current (see Figure 12) where it can request some energy to move forward.

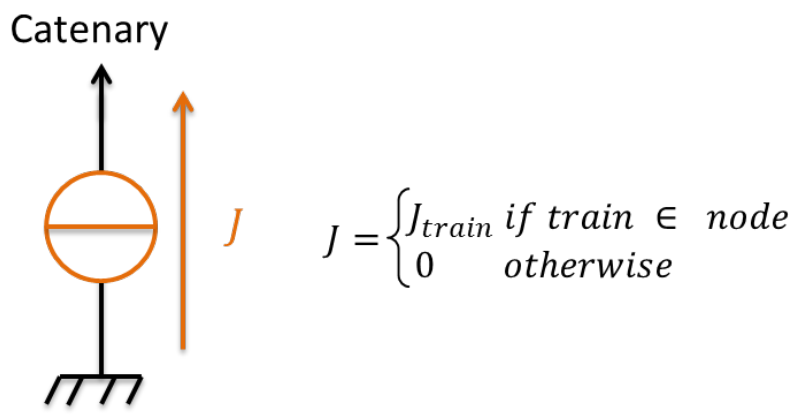

Figure 12: Train model

The substations are the energy sources. Therefore, associated with their fixed current nodes (node where a train can be attached), there is also a voltage source with a small impedance and a rectifier (non-reversible station). To avoid the discontinuity of the rectifier, the same function than in [4] has been introduced. 


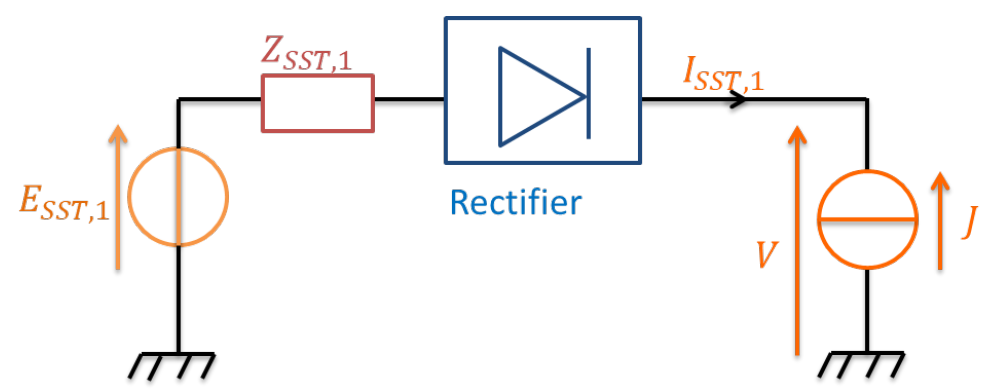

Figure 13: Substation model

With:

\begin{tabular}{|c|c|c|}
\hline EssT,1 & $(\mathrm{V})$ & Nominal voltage of the substation 1 \\
\hline$Z_{S S T, 1}$ & $(\Omega)$ & Impedance of the substation 1 \\
\hline ISST,1 & $(\mathrm{A})$ & Current provided by the substation 1 \\
\hline $\mathrm{V}$ & (V) & Voltage of the node of current associated with the substation \\
\hline $\mathrm{J}$ & $(\mathrm{A})$ & Current of the node of current associated with the substation \\
\hline
\end{tabular}

\section{Solving}

The nodal representation leads to equation (1).

$$
A\left(\begin{array}{c}
V_{\text {node }} \\
I_{S S T}
\end{array}\right)=\left(\begin{array}{c}
J_{\text {node }} \\
E_{S S T}
\end{array}\right)
$$

With:

\begin{tabular}{|l|l|l|}
\hline A & - & Matrix of admittances and impedances \\
\hline Vnode & Vector of voltages of the fixed and mobile current nodes \\
\hline ISST & (A) & Vector of currents of the substations \\
\hdashline$J_{\text {node }}$ & $\begin{array}{l}\text { Vector of currents requested by the trains to feed their auxiliaries and traction } \\
\text { motor }\end{array}$ & \\
\hdashline EsST & Vector of nominal voltages of the substations &
\end{tabular}

A gathers all the electrical resistances of the railway line. The objective is to determine the voltage of the nodes $\left(\mathrm{V}_{\text {node }}\right)$ and the current provided by the substations ( $\left.\mathrm{I}_{\mathrm{SST}}\right)$.

However, the currents requested by the trains are unknown, but the railway mission gives their demand of power. So, equation (1) becomes:

$$
A X=\left(\begin{array}{c}
P_{\text {noda }} / V_{\text {node }} \\
E_{S S T}
\end{array}\right)
$$

With $\mathrm{P}_{\text {node }}(\mathrm{W})$ the vector of powers at each node. When a train is connected to a node, its power corresponds to the train power; otherwise, its power is equal to zero. This implicit equation is solved using a Newton-Raphson algorithm with function (3).

$$
F(X)=A X-S
$$

\begin{tabular}{|c|c|c|}
\hline A & - & Matrix of admittances and impedances \\
\hline $\mathrm{X}^{\mathrm{T}}=\left(\mathrm{V}_{\text {node }} \mathrm{I}_{\mathrm{SST}}\right)$ & $(\mathrm{V}, \mathrm{A})$ & Vector of unknown variables \\
\hline $\mathrm{S}^{\mathrm{T}}=\left(\mathrm{P}_{\text {node }} / \mathrm{V}_{\text {node }} \mathrm{E}_{\mathrm{SST}}\right)$ & $(\mathrm{A}, \mathrm{V})$ & Second member \\
\hline
\end{tabular}

With: 


\section{ENERGY MANAGEMENT}

\section{State of the art and choice of the energy management method}

The energy management has a strong influence on the sizing [2]. So, in the paper, to take into account this influence, an energy management is added to the sizing model. Several methods are possible. They can be classified into two main families: the optimal energy management method and the rule-based management.

The optimal energy management methods, such as dynamic programming [12], [13], [14], Pontryagin's principle [15], linear quadratic [16],.. use optimization technics to find the best repartition of power between the energy sources. To do so, the problem needs to be formulated in a specific way: it is necessary to determine an objective function (to minimize or maximize), and eventually constraints (equalities or inequalities). This may lead to a reformulation of the problem using mathematics tools such as state equations, Lagrangian, Hamiltonian... [15].

The main advantage of optimal energy management methods is their global view of the cycle. Indeed, they take into account all the time steps of the railway mission. This way, they are able to adapt to the distribution of the demand between the energy sources in order to avoid their oversizing.

However, the chosen method integrates the energy management into the sizing model. Then, an optimization algorithm solves this global model. In the paper, the application studied is a railway line with several trains traveling on it. It means that the variables are vector variables in space and time. Their size of depends on the distance of the railway line but also of the number of time step of the cycle. Moreover, the number of these variables depends on the number of trains of the study case. Therefore, the optimization-oriented model is composed of several inputs and numerous constraints. Thus, the optimization algorithm chosen is gradientbased due to its capability to deal with a complex model with a huge number of variables. This implies that the energy management has to be derivable. Moreover, the objective is to use this method for an industrial application to do the pre-sizing of hybrid trains. So, to be efficient, the optimization model has to compute fast and to not require a lot of hard disk memory. Optimal energy management methods are not always derivable and can request some computation time. So, in this paper, a rule-based management has been chosen.

Rule-based management is widely used especially for transport applications [17], [18]. It consists of a series of comparisons and according to the results of these comparisons, a specific behavior of each energy sources is imposed (see Figure 14). Contrary to optimal management methods, rule-based management takes a decision time step by time step without any global look on the railway mission. This can lead to an oversizing of the energy sources. However, it demands few memory disk and can be easily derivable. It is also possible to apply it in real-time.

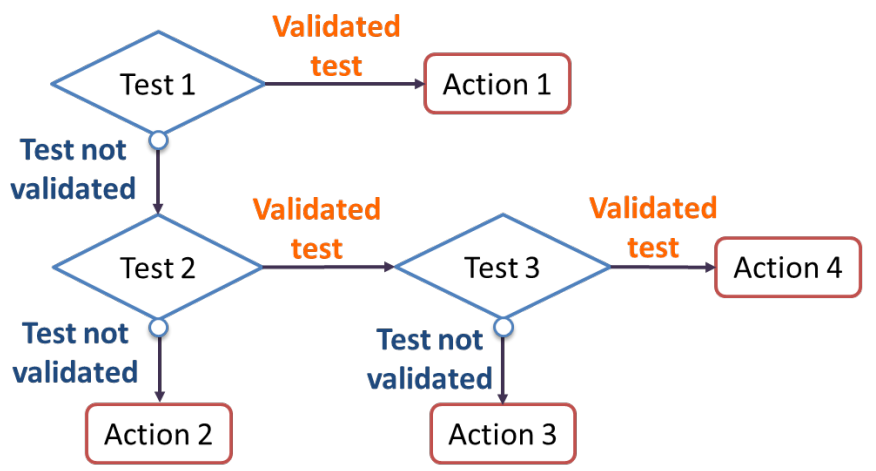

Figure 14: Rule-based management principle 


\section{Rule-based management}

This type of energy management is widely used for multi-source vehicle [19], [20]. Moreover, it is interesting for SNCF because of its implementation easiness. The energy management aims to support the voltage of the catenary. To do so, this management uses voltage thresholds to determine the distribution of power between the energy storage system and the substations (see Figure 15).

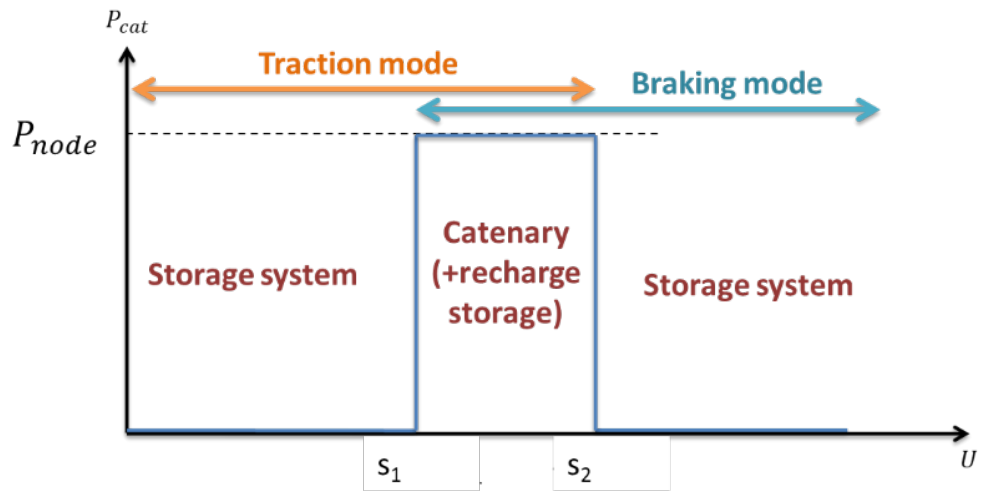

Figure 15: Energy management

When the voltage is below the threshold $\mathrm{s}_{1}$, the energy storage system provides the power requested by the train. When the voltage is between $\left[\mathrm{s}_{1} ; \mathrm{s}_{2}\right]$, the catenary provides or receives the train power. Finally, when the voltage is above the threshold $s_{2}$, the energy storage system receives the braking power (as much as possible to partially feed the traction motor and dissipate the rest through a rheostat).

However, this energy management applies an all-or-none principle, which can lead to strong voltage oscillations. Indeed, if the voltage is below $\mathrm{s}_{1}$, it means that the catenary is not solicited. So, its voltage reaches the voltage level of the substations. Thus, at the next time step, the voltage is between $\left[\mathrm{s}_{1} ; \mathrm{s}_{2}\right]$ and so the catenary is used. This leads to a decrease of voltage at the consumption point and so, to a voltage below $\mathrm{s}_{1}$. So, at the following time step, it is impossible to use the catenary. Thus, this oscillation process starts again (energy storage system feed - catenary feed - energy storage system feed, see Figure 16).

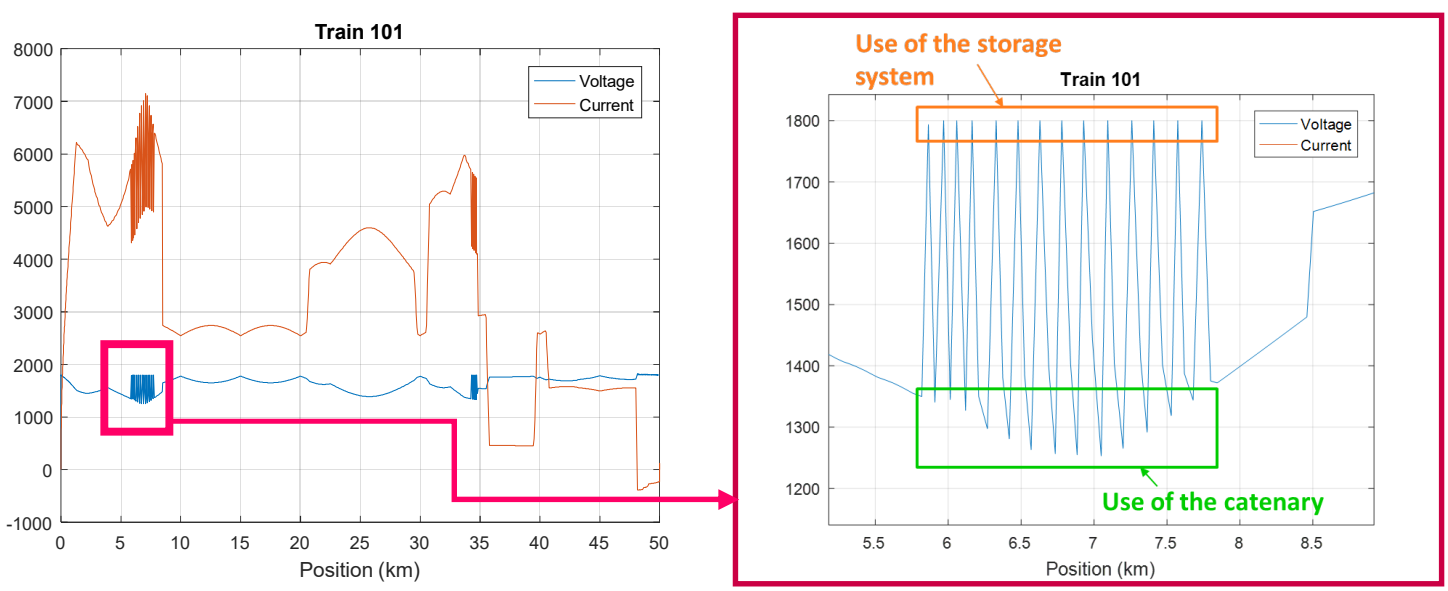

Figure 16: Voltage oscillations 
To avoid such oscillations, the power is split up between the catenary and the energy storage system: the catenary provides the power in such a way the voltage stays above $s_{1}$ and the energy storage system provides the energy complement (cf. Figure 17).
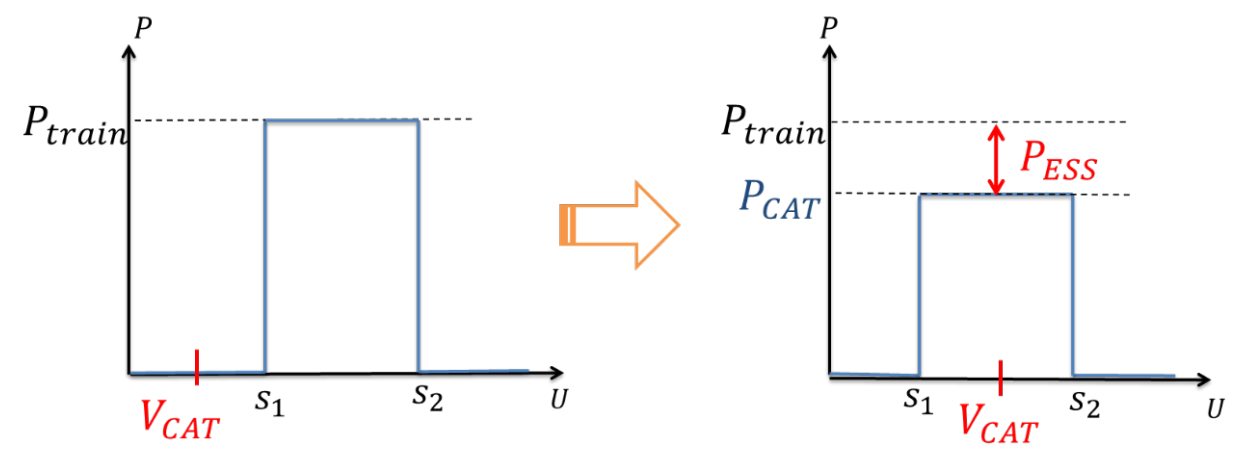

Figure 17: Distribution of power

With:

\begin{tabular}{|c|c|c|}
\hline $\mathrm{V}_{\mathrm{CAT}}$ & $(\mathrm{V})$ & Voltage of the catenary at the point of energy consumption \\
\hline $\mathrm{P}_{\mathrm{CAT}}$ & $(\mathrm{W})$ & Power provided (or received) by the catenary \\
\hline PESS & (W) & Power provided (or received) by the storage system \\
\hline
\end{tabular}

Therefore, there are three traction modes:

- $\quad$ the requested power can be provided by the catenary only,

- $\quad$ it can be provided by both the catenary and the energy storage system,

- $\quad$ it is also possible to charge the storage system using the catenary.

It is also possible to separate the braking into three modes:

- the braking power can be sent fully to the electrical line,

- $\quad$ it can be sent partly to the electrical line (the storage system do the complement as much as possible and the rest is dissipated through a rheostat),

- $\quad$ it is also possible that the braking power is fully sent to the storage system and the dissipating rheostat.

\section{OPTIMIZATION ORIENTED MODEL}

\section{Inputs and constraints}

The optimization is made using a railway mission (time cycle) which gives the power and position of the different trains circulating on the line (see Figure 6a and Figure 6b). This railway mission is composed of 25 trains of 4 different types (A, B, C, and D) which have a different maximum power. The railway line is composed of 6 substations (voltage of $1500 \mathrm{~V}$ DC) and one paralleling station distributed along the $120 \mathrm{~km}$ of railway track.

The issue is to determine the sizing of the embedded storage system but also the energy management to apply. So, the optimization variables are: 
- the number of cells of the storage systems for each type of train. The sizing of the embedded storage system for each kind of train is determined by its maximum power or its maximum energy.

- the thresholds of the energy management $\left(\mathrm{s}_{1}, \mathrm{~s}_{2}\right)$.

Adding storage elements in the train aims to support the catenary voltage. The voltages at the nodes have to respect some limits given by a railway standard [21]. Thus, there are 3 constraints on the measured nodes voltages:

- the minimum voltage has to be above $1000 \mathrm{~V}$

- the average voltage has to be above $1350 \mathrm{~V}$

- the maximum voltage has to be below $1950 \mathrm{~V}$.

Moreover, in order to be able to restart a new railway mission with a full capacity, the state of charge of each storage system has to finish the mission at its initial level. So, for each train: the difference between the final and initial state of charge has to be constrained to be close to zero.

Finally, the rule-based management determines the amount of power provided by each energy source (substations through the catenary or energy storage systems). However, the power and energy capacity demanded during the railway mission to the energy storage systems have to correspond to their sizing. So, constraints have been added on the maximum traction power and maximum energy used during the railway mission to ensure that the sizing is able to answer the demand.

The optimization objective chosen is the energy consumption at the substations (see (4)).

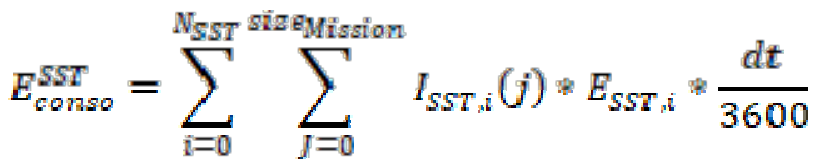

With:

\begin{tabular}{|c|c|c|}
\hline 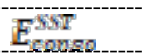 & (Wh) & Energy consumption of all the substations for the railway mission \\
\hline $\mathrm{I}_{\mathrm{SST}, \mathrm{i}}$ & $(\mathrm{A})$ & Current of the substation $\mathrm{i}$ \\
\hline ESST,i $_{\text {S }}$ & (V) & Voltage of the substation $\mathrm{i}$ \\
\hline $\mathrm{dt}$ & $(\mathrm{s})$ & Time step of the mission, \\
\hline $\mathrm{N}_{\text {SST }}$ & - & Number of substations on the railway line \\
\hline size $\mathrm{mission}$ & - & Number of time steps of the railway mission \\
\hline
\end{tabular}

Figure 18 presents the complete optimization oriented model. 


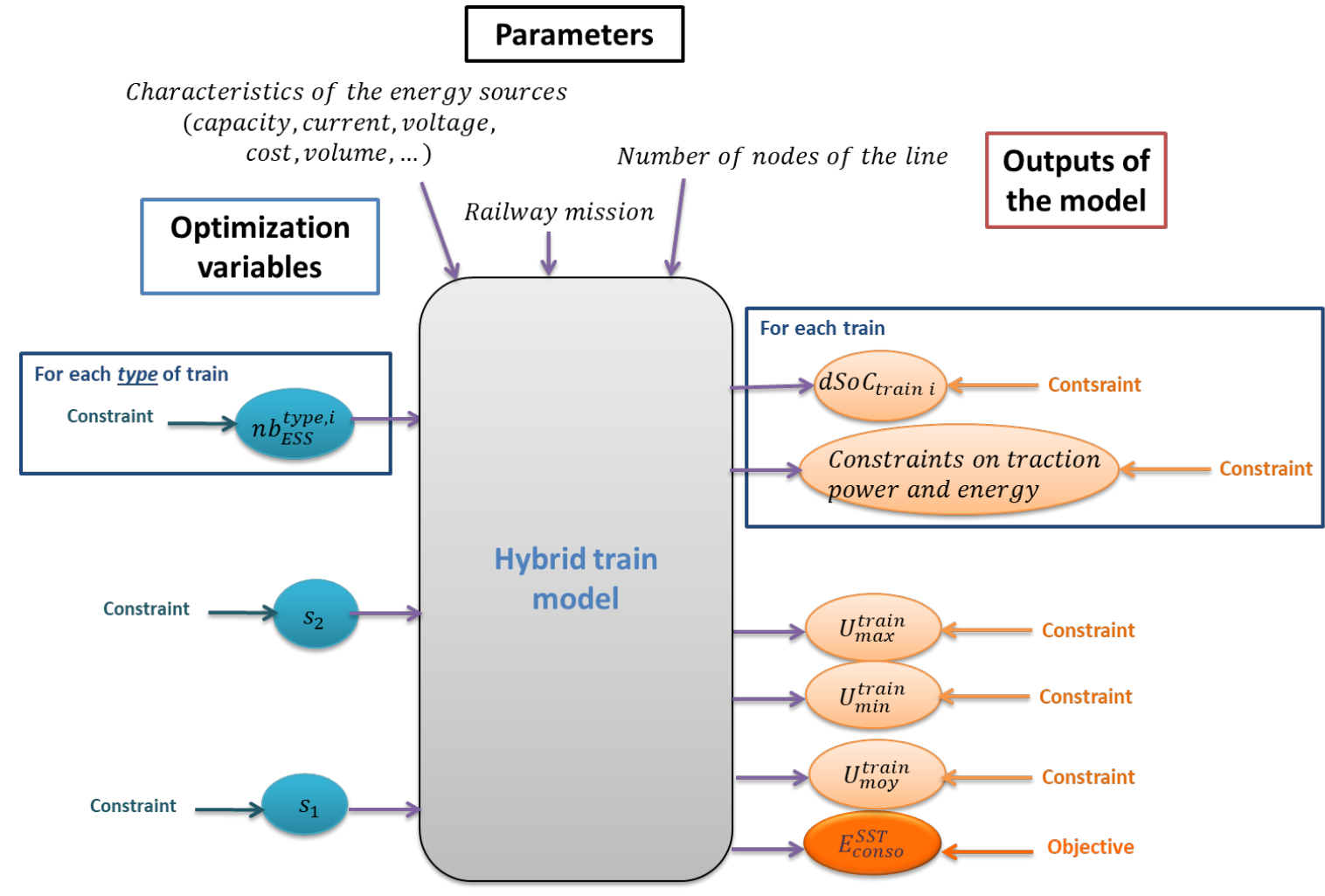

Figure 18: Optimization oriented model

\section{Jacobian}

Due to the several inputs variables and the numerous constraints (for instance, this study case has 81 constraints), a gradient-based algorithm has been chosen. Therefore, it is necessary to compute the jacobian of the global model. Several methods are possible such as automatic derivation of the code with ADOL-C [22] which give the exact jacobian matrix. This derivation method creates a derivation tree. So, for our application, a branch appears for every possibility of each train and for all time step. This requires a lot of hard disk memory (e.g., this study case has a derivation tree that needs more than 250Go). So, this method cannot be applied. Thus, to compute the jacobian, an approximation method has been used (finite differences) even if the exact jacobian ensures a faster convergence of the algorithm [23].

\section{RESULTS AND DISCUSSION}

The optimization has been performed using interior point optimization in the MATLAB environment (with fmincon function [24]). It took $2 \mathrm{~h} 35 \mathrm{~min}$ to perform one optimization on a computer with an Intel ${ }^{\circledR}$ Xeon ${ }^{\circledR}$ CPU ES-2698v4@2.20GHz (2 processors) with 256Go of RAM and with a 64bit exploitation system. The results are presented in Table 1. The optimization has been performed with batteries (see Table 2 for their characteristics) and then with supercapacitors (see Table 3 for their characteristics).

Table 1: Optimization results

\begin{tabular}{|l|l|l|l|}
\hline Variable & Unit & Case of batteries & Case of supercapacitors \\
\hline Number of cells of A type & - & $4620(215 \mathrm{kWh} / 905 \mathrm{~kW})$ & $640(2.8 \mathrm{kWh} / 1.4 \mathrm{MW})$ \\
\hline Number of cells of B type & - & $5240(240 \mathrm{kWh} / 1 \mathrm{MW})$ & $2900(12.6 \mathrm{kWh} / 6.2 \mathrm{MW})$ \\
\hline
\end{tabular}




\begin{tabular}{|l|l|l|l|}
\hline Number of cells of C type & - & $5430(250 \mathrm{kWh} / 1 \mathrm{MW})$ & $1500(6.5 \mathrm{kWh} / 3.2 \mathrm{MW})$ \\
\hline Number of cells of D type & - & $\begin{array}{l}12500 \\
(575 \mathrm{kWh} / 2.4 \mathrm{MW})\end{array}$ & $19900(86.4 \mathrm{kWh} / 4.3 \mathrm{MW})$ \\
\hline $\mathrm{s}_{1}$ & $\mathrm{~V}$ & 1001 & 1002 \\
\hline $\mathrm{s}_{2}$ & $\mathrm{~V}$ & 1501 & 1501 \\
\hline
\end{tabular}

\begin{tabular}{|l|l|l|l|}
\hline Consumed energy & MWh & 20 & 20 \\
\hline Minimum voltage $(\geq 1000)$ & $\mathrm{V}$ & 1072 & 1072 \\
\hline Average voltage $(\geq 1350)$ & $\mathrm{V}$ & 1350 & 1352 \\
\hline Maximum voltage $(\leq 1950)$ & $\mathrm{V}$ & 1876 & 1876 \\
\hline $\begin{array}{l}\text { Difference between the initial and } \\
\text { final state of charge (for each train) }\end{array}$ & $\mathrm{Wh}$ & 0.0 & 0.0 \\
\hline Constraint on power & $\mathrm{W}$ & $\leq 0$ & $\leq 0$ \\
\hline Constraint on energy & Wh & $\leq 0$ & $\leq 0$ \\
\hline
\end{tabular}

The voltage of the different trains are presented in Figure 19a (case of batteries) and in Figure 19b (case of supercapacitors).
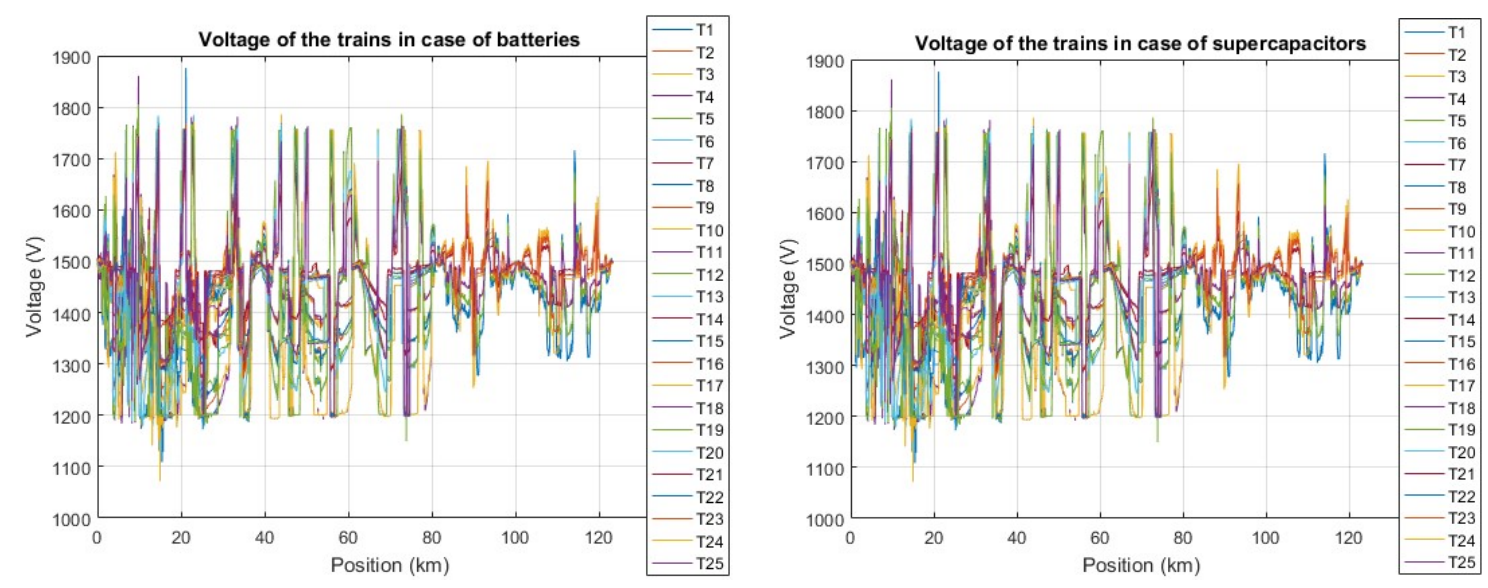

Figure 19a: Voltage in case of batteries

Figure 19b: Voltage in case of supercapacitors

Table 2: Batteries characteristics

\begin{tabular}{|l|l|l|}
\hline Nominal capacity (Ah) & Nominal current (A) & Nominal voltage (V) \\
\hline 20 & 85 & 2.3 \\
\hline
\end{tabular}

Table 3: Supercapacitors characteristics

\begin{tabular}{|l|l|l|}
\hline Nominal capacity per cell $(\mathbf{F})$ & Nominal voltage $(\mathbf{V})$ & Nominal resistance $(\mathbf{\Omega})$ \\
\hline 5000 & 2.5 & $350^{*} 10^{-6}$ \\
\hline
\end{tabular}


For both optimizations, the constraints on the state of charge and the power/energy of the storage system are fully respected. Moreover, the voltage restrictions (minimum, average and maximum) are also above/below the requested standards. The first threshold of the energy management is close to the minimum limits and the second threshold to the voltage of the substations. These two limits are almost the same for batteries and supercapacitors. They do not seem to have a huge impact on the constraints but also on the objective.

For the train of type A, B and C, the number of cells is highly inferior in case of supercapacitors compared to batteries. Table 4 and Table 5 present respectively the different masses and volumes for both cases.

Table 6: Volume of the energy storage system

\begin{tabular}{|l|l|l|l|}
\hline Variable & Unit & Case of batteries & Case of supercapacitors \\
\hline Volume of energy storage system for ZGC US & $\mathrm{m}^{3}$ & 12 & 0.6 \\
\hline Volume of energy storage system for ZGC UM & $\mathrm{m}^{3}$ & 13.6 & 2.9 \\
\hline Volume of energy storage system for Regio US & $\mathrm{m}^{3}$ & 14.1 & 1.5 \\
\hline Volume of energy storage system for Regio UM & $\mathrm{m}^{3}$ & 32.5 & 19.7 \\
\hline
\end{tabular}

Table 7: Mass of the energy storage system

\begin{tabular}{|l|l|l|l|}
\hline Variable & Unit & Case of batteries & Case of supercapacitors \\
\hline Mass of energy storage system for ZGC US & T & 5 & 0.7 \\
\hline Mass of energy storage system for ZGC UM & T & 5.8 & 3 \\
\hline Mass of energy storage system for Regio US & T & 6 & 1.6 \\
\hline Mass of energy storage system for Regio UM & T & 13.8 & 20.9 \\
\hline
\end{tabular}

In the case of supercapacitors, the mass and volume of these trains are lower. Since the energy storage system are embedded in the trains, it is more suitable to have supercapacitors than batteries for these trains. This difference is due to the kind of demand of their railway mission. Indeed, the demand seems to concern peaks of power but do not request a lot of energy. The supercapacitors with their high density of power are more adapted.

However, in the case of type D trains, the number of cells is very high. It seems that this kind of train requests a high power and also a huge amount of energy. Neither batteries nor supercapacitors are adapted. Indeed, it is not possible to add on-board an indefinite number of storage system because of the restriction on available volume and mass. A combination of these two technologies may be more interesting or perhaps another type of energy storage system such as flywheel.

\section{CONCLUSIONS}

Using an embedded storage system is a performing way to support the voltage of the catenary and the main advantage is that its action is not limited to a specific area. To determine the sizing of this element, an optimization method has been used based on the nodal representation. Moreover, to take into account the influence of the energy management, a rule-based method has been added to the model. Finally, the optimization has been performed to determine the value of the sizing variables as well as the value of the thresholds of the energy management. The IPOPT algorithm has been chosen to do this optimization due to the complexity of the railway mission. This method helps to determine the most adapted technology of storage 
system according to the type of train and their demand profile. For the studied railway mission, the supercapacitors seem to be the better choice.

The energy management used in this paper is a rule-based method. This kind of management takes a decision time step by time step without taking into account the previous or next time steps. So, the decision which is made could not be optimal. It will be interesting to change the energy management for an optimal method that will have a global view of the entire cycle instead of considering only one time step.

Finally, the use of IPOPT imposes to compute the jacobian matrix. Instead of using an approximated method, an improvement will be to compute the exact jacobian to ensure a faster convergence. A possible method is to use Tapenade or to compute it "manually".

\section{REFERENCES}

[1] SNCF réseau, "sncf-reseau.fr," [Online]. Available: sncf-reseau.fr/fr/le-reseau. [Accessed 03 Avril 2018 ].

[2] SNCF Réseau, "Toutes nos cartes ferroviaires," [Online]. Available: https://www.sncf-reseau.fr/fr/projets-chantiersferroviaires/cartes?field_localisation_carte_tid\%5B\%5D=148. [Accessed 25 Juin 2018].

[3] "SNCF, Le TER en 2030, Rapport technique, SNCF Proximtés, 2008".

[4] O. Bossi, Contribution au dimensionnement et à la gestion par optimisation de systèmes de stockage d'énergie pour les réseaux électriques ferroviaires, Grenoble, 2016.

[5] P.-V. BUZILA, Gestion énergétique optimale des Installations Fixes de Traction Electrique Ferroviaire Hybrides, Lille, 2015.

[6] O. Bossi, J. Pouget, N. Retiere and L. Gerbaud, "Optimal power flow with storage in DC electrified railways," COMPEL : The intertional journal for computation and mathematics in electrical and electronic engineering, vol. 35, pp. 885-897, 2016.

[7] L. Pugi, A. Frilli, D. Nocciolini and A. Rindi, "Development and validation of a model for the optimization of regenrative braking oof high speed trains," IEEE 16th International Conference on Environment and Electrical Engineering (EEEIC), 7-10 June 2016.

[8] Z. Tian, S. Hillmansen, C. Roberts, P. Weston, L. Chen, N. Zhao, S. Shu and T. Xin, "Modeling and simulation of DC railway systems for energy saving," IEEE 17th International Conference on Intelligent Transportation Systems (ITSC), 8-11 October 2014.

[9] A. Frilli, Z. Meli, D. Nocciolini, S. Panconi, L. Pugi and A. Rindi, "An extended library of models of railway vehicles for fast simulation and optimization of regenerative braking and energy management," AEIT International Annual Conference, 5-7 October 2016.

[10] B. Desjouis, G. Remy, F. Ossart, C. Marchand, J. Bigeon and E. Sourdille, "A new generic problem formulation dedicated to electrified railway systems," 2015 International Conference on Electrical Systems for Aircraft, Railway, Ship Propulsion and Road Vehicles, 3-5 March 2015.

[11] R. A. Jabr and I. Dzafic, "Solution of DC railway traction power flow systems including limited network receptivity," IEEE Transactions on Power Systems, pp. 1-1, 28 March 2017. 
[13] V. Reinbol, Méthodology de dimensionnement d'un moteur électrique pour véhicules hybrides : optimisation conjointe des composants et de la gestion d'énergie, 2015.

[14] Y. Noda et M. Miyatake, «Methodology to apply dynamic programming to the energy-efficient driving technique of lithium-ion battery trains,» 2016 International Conference on Electrical Systems for Aircraft, Railway, Ship Propulsion and Road Vehicles \& International Transportation Electrification Conference (ESARS-ITEC) , 2-4 Novembre 2016.

[15] L. S. Pontryagin, Mathematical Theory of Optimal Processes, CRC Press, 1987.

[16] T. Zeng, D. Upadhyay et G. Zhu, «Linear quadratic air-path control for diesel engines with regenrative and assisted turbocharger,» IEEE 56th Annual Conference on Decision and Control, 12-15 December 2017.

[17] H. Alloui, F. Khoucha, N. Rizoug, M. Benbouzid et A. Keloui, «Comparative study between rule-based and frequency separation energy management strategies within fuel-cell/battery electric vehicle,» IEEE International Conference on Environment and Electrical Engineering, 13 July 2017.

[18] H. Hemi, J. Ghouili et A. Cheriti, «A real time energy management for electrical vehicle using combination of rule-based and ECMS,» IEEE Electrical Power \& Energy Conference, 08 May 2014.

[19] H. Alloui, F. Khoucha, N. Rizoug, M. Benbouzid and A. Keloui, "Comparative study between rule-based and frequency separation energy management strategies within fuel-cell/battery electric vehicle," IEEE International Conference on Environment and Electrical Engineering, 13 July 2017.

[20] H. Hemi, J. Ghouili and A. Cheriti, "A real time energy management for electrical vehicle using combination of rule-based and ECMS," IEEE Electrical Power \& Energy Conference, 08 May 2014.

[21] Technical Committee CLC/TC 9X, Railway applications - Fixed installations - Requirements for the validation of simulation tools used for the design of traction power supply systems, Paris, 2016.

[22] B. Delinchant, D. Lahaye, F. Wurtz et J.-L. Coulomb, «Manifold mapping optimization with or without true gradients,» Mathematics and Computers Simulation, $\mathrm{n}^{\circ} \% 190$, pp. 256-265, 2013.

[23] «Adol-C - COIN-OR,» [En ligne]. Available: https://projects.coin-or.org/ADOL-C. [Accès le 18 October 2017].

[24] Matworks, "fmincon," [Online]. Available: https://fr.mathworks.com/help/optim/ug/fmincon.html. [Accessed 06 Juillet 2018]. 